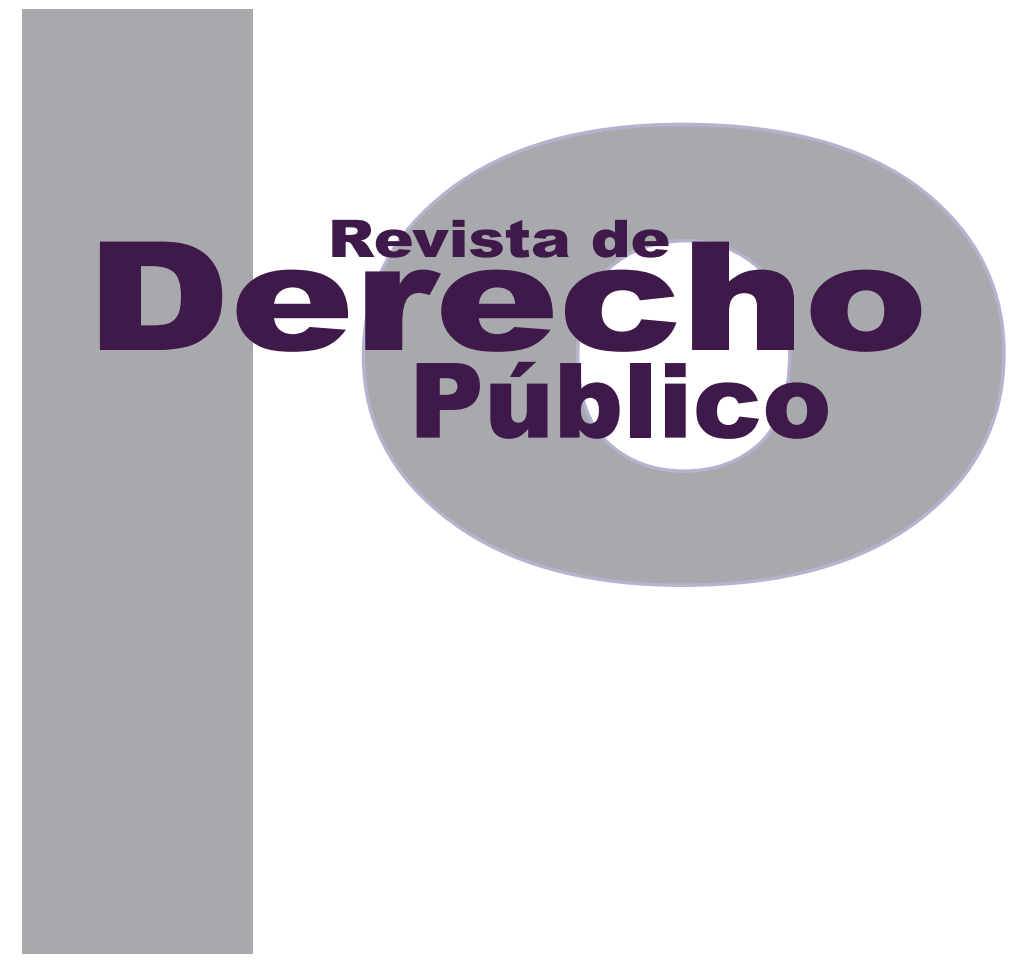

INEXISTENCIA DE DERECHOS ADQUIRIDOS: TÍTULOS MINEROS VIGENTES EN ÁREAS POSTERIORMENTE DECLARADAS EXCLUIBLES DE MINERÍA

\author{
Mayra Alejandra luna Gélvez \\ NATAlia CoRrea SÁnchez
}

Artículo de reflexión

DOI: http://dx.doi.org/10.15425/redepub.34.2015.31

Universidad de los Andes

Facultad de Derecho

Revista de Derecho Público N. ${ }^{\circ} 34$

Enero - Junio de 2015. ISSN 1909-7778 


\section{Inexistencia de derechos adquiridos: títulos mineros vigentes en áreas posteriormente declaradas excluibles de minería}

\section{Resumen}

Este texto estudia las nociones de "área de especial importancia ecológica”, "zona excluible de minería” y “título minero", con el fin de mostrar la tensión que existe entre dos actividades de interés público: la actividad minera y el deber de protección de las áreas de especial importancia ecológica. Asimismo, analiza si la obtención del título minero y de la licencia ambiental crea o no derechos adquiridos en cabeza del concesionario minero. Esto con el objetivo de determinar si se pueden modificar las condiciones de ejecución del contrato de concesión minera, en virtud de la protección de un área de especial importancia ecológica declarada y delimitada con posterioridad a la obtención del título minero.

Palabras clave: área de especial importancia ecológica, zona excluible de minería, título minero o contrato de concesión minera, derechos adquiridos, interés público, derecho público.

\section{Inexistence of Acquired Rights: Current Mining Concessions within Excludable Mining Areas}

\section{Abstract}

This paper studies the concepts of "special ecological importance area", "excludable mining zone" and "mining concession", to show the tension between two activities of public interest: the mining activity and the protection duty over special ecological importance areas. Also, the paper analyzes whether mining concessions and environmental licenses create or not, acquired rights for the mining concessioner. This, to conclude if the execution conditions of the mining concessions can be modified due to the creation of a new special ecological importance area, declared and defined as such after the creation of the mining contract.

Keywords: special ecological importance area, excludable mining zone, mining concession, acquired rights, public interest, public law.

\section{Inexistência de direitos adquiridos: títulos mineiros vigentes em áreas posteriormente de- claradas excluídas de mineração}

\section{Resumo}

Este texto estuda as noções de "área de especial importância ecológica", "zona excluída de mineração" e "título mineiro", com o fim de mostrar a tensão que existe entre duas atividades de interesse público: a atividade mineira e o dever de proteção das áreas de especial importância ecológica. Assim mesmo, analisa se a obtenção do título mineiro e da licença ambiental cria ou não direitos adquiridos em cabeça do concessionário mineiro. Isto com o objetivo de determinar se as condições de execução do contrato de concessão mineira podem ser modificadas, em virtude da proteção de uma área de especial importância ecológica declarada e delimitada com posterioridade à obtenção do título minero.

Palavras-chave: área de especial importância ecológica, zona excluída de mineração, título mineiro ou contrato de concessão mineira, direitos adquiridos, interesse público, direito público. 


\title{
Inexistencia de derechos adquiridos: títulos mineros vigentes en áreas posteriormente declaradas excluibles de minería*
}

\author{
Mayra Alejandra Luna Gélvez** \\ Natalia Correa Sánchez ${ }^{* *}$
}

\section{SUMARIO}

Introducción - I. ÁREAS DE ESPECIAL IMPORTANCIA ECOLÓGICA Y ZONAS EXCLUIBLES DE MINERÍA - II. EL TÍTULO MINERO O EL CONTRATO DE CONCESIÓN MINERA - III. EL ALCANCE DE LOS BENEFICIOS QUE EL CÓDIGO DE MINAS CONCEDE AL PRIMER SOLICITANTE Y AL TITULAR MINERO - A. El Código de Minas consagra la aplicación preferente de sus disposiciones normativas - B. El Código de Minas impone un límite a las autoridades públicas para establecer y exigir permisos, licencias o requisitos adicionales para el desarrollo de la actividad minera - C. El Código de Minas crea para el futuro titular un derecho de prelación de la primera solicitud de propuesta - D. El Código de Minas inaplica el Estatuto General de Contratación de la Administración Pública en los temas mineros - E. Según el Código de Minas, la minería es una actividad de utilidad pública - F. Del título minero nace un derecho personal - IV. LA DISCUSIÓN SOBRE LOS DERECHOS ADQUIRIDOS DEL CONCESIONARIO MINERO - A. El contrato de concesión minera consolida derechos adquiridos - B. El contrato de concesión minera no crea derechos adquiridos - 1. El poder dispositivo de la Administración - 2. El poder policivo de la Administración - 3. Los principios de concurrencia y la participación ciudadana - V. LA DILUCIÓN DE LOS DERECHOS ADQUIRIDOS DEL CONCESIONARIO MINERO EN LAS DIFERENTES ETAPAS DE LA ACTIVIDAD MINERA - A. La propuesta - B. La exploración - C. Etapa de construcción, montaje y explotación - 1. Título minero vigente en etapa de explotación, pero sin el respectivo permiso ambiental - 2. Título minero vigente en etapa de explotación y con el respectivo permiso ambiental - 3. Cambio normativo en etapa de construcción y montaje o de explotación con el PTo aprobado y con el respectivo permiso ambiental - 4. Los derechos adquiridos y la posterior declaratoria de reserva forestal protectora - 5. El incumplimiento de los requisitos exigidos para desarrollar la actividad minera - VI. CONCLUSIONES - Referencias.

Cómo citar este artículo: Luna Gélvez, M. A. y Correa Sánchez, N. (Junio, 2015). Inexistencia de derechos adquiridos: títulos mineros vigentes en áreas posteriormente declaradas excluibles de minería. Revista de Derecho Público, 34. Universidad de los Andes (Colombia).

** Abogada y literata de la Universidad de los Andes. Ha sido consultora del Banco Mundial para el fortalecimiento de competencias asociadas a la justicia transicional y al acceso a la justicia en escenarios de posconflicto. También ha sido editora del Instituto Colombiano de Derecho Tributario. Correo: ma.luna94@gmail.com

*** Abogada y candidata a magíster en Políticas Públicas de la Universidad de los Andes. Ha sido consultora del Banco Mundial para la implementación del Código General del Proceso. Actualmente se desempeña como tutora del Centro de Español de la Universidad de los Andes. Correo: ncorreasanchez@ gmail.com 
Introducción

El artículo 79 de la Constitución Nacional (CN) dice que es un deber del Estado proteger y conservar las áreas de especial importancia ecológica. Asimismo, la Corte Constitucional manifestó en la sentencia C-339 de 2002 que no se pueden realizar actividades de exploración y explotación en áreas declaradas y delimitadas como "excluibles de minería". A pesar de estos mandatos constitucionales, dirigidos a la protección y preservación del medio ambiente, en Colombia existen solicitudes de concesión y títulos mineros vigentes dentro de áreas excluidas de minería y, por tanto, de especial importancia ecológica. La razón por la que se siguen desempeñando actividades mineras dentro de estos ecosistemas protegibles es porque se considera que existen derechos adquiridos de aquellos concesionarios a quienes se les titula un área geográfica, que posteriormente se declara zona excluible de minería.

En atención a este problema, el presente documento analiza si la obtención del título minero y la licencia ambiental, necesaria en las etapas de exploración, construcción, montaje y explotación, crea o no derechos adquiridos oponibles ante la posterior declaratoria del área de especial importancia ecológica o zona excluible de minería (L. 685/2001, art. 34).

Para desarrollar ese objetivo, el texto se divide en seis partes. La primera parte aclara los conceptos relativos a las áreas de especial importancia ecológica y zonas de exclusión minera. La segunda parte sitúa conceptualmente al lector, de modo que desarrolla la noción y las características del título minero o contrato de concesión minera. La tercera parte se refiere a los beneficios que el Código de Minas otorga al concesionario minero, así como a los parámetros de interpretación que ha dado la Corte Constitucional para que tales beneficios no se conviertan en derechos ilimitados que protegen al titular minero ante cualquier cambio legislativo posterior y adverso. La cuarta parte desarrolla la noción de derechos adquiridos y presenta las dos posturas existentes sobre los alcances de los derechos del concesionario minero. La quinta parte problematiza la existencia de derechos adquiridos en las etapas que componen la actividad minera y presenta algunos escenarios que han tratado el tema de los títulos en áreas excluibles de minería. La sexta parte presenta las conclusiones.

\section{I. ÁREAS DE ESPECIAL IMPORTANCIA ECOLÓGICA Y ZONAS EXCLUIBLES DE MINERÍA}

El artículo 79 de la Constitución Nacional y el artículo 5 de la Ley 99 de 1993 disponen que el Estado y la autoridad ambiental tienen el deber de proteger y conservar las áreas de especial importancia ecológica. Según la sentencia T-666 de 2002, las áreas de especial importancia ecológica están sometidas a un régimen de protección más intenso que el resto del medio ambiente. Dicha protección se convierte en un principio interpretativo obligatorio cuando se está frente a la aplicación e interpretación de normas que afectan esas zonas (CConst., T-666/02, E. Montealegre). 
Por otro lado, las zonas excluibles de minería, que son áreas de especial importancia ecológica, se definen en el artículo 34 del Código de Minas (Ley 685 de 2001) como aquellas áreas en las que no se pueden desarrollar trabajos y obras de exploración y explotación minera, porque se han declarado y delimitado, según la normatividad vigente, como de protección de los recursos naturales y del ambiente. Entre las zonas excluibles de minería se cuentan las que integran el sistema de parques nacionales naturales, los parques naturales de carácter regional y las zonas de reserva forestal. Bajo los criterios de la Corte Constitucional se considera que "además de las zonas de exclusión previstas en esta ley, pueden existir otras, ya declaradas con anterioridad o que se declaren en el futuro por la autoridad ambiental" (CConst., C-339/02, J. Araújo). Esto quiere decir que se pueden salvaguardar, entre otros, los ecosistemas que requieren protección bajo los compromisos internacionales y que, aunque no han sido declarados o no cuentan con una categoría especialmente aplicada, sí son identificables y potencialmente delimitables (Jiménez, Jiménez y Puentes, 2011, págs. 2-3).

El artículo 34 del Código de Minas, no obstante, fue modificado en 2010 por el artículo 3 de la Ley 1382. Esta ley incluyó como áreas excluibles de minería los ecosistemas de páramo y los humedales designados dentro de la lista de importancia internacional de la Convención Ramsar. ${ }^{1}$ Sin embargo, la Corte Constitucional decla-

Siempre y cuando se delimiten geográficamente por la autoridad ambiental con base en estudios técnicos, sociales y ambientales. ró la inexequibilidad diferida de la Ley 1382 de 2010 (CConst., C-366/12, L. E. Vargas), que salió del ordenamiento jurídico nacional el 11 de mayo de 2013. Esta decisión se fundamentó en que el proyecto de lo que sería la Ley 1382 de 2010 no se consultó con las comunidades étnicas, aunque regulaba temas relacionados con la actividad minera, cuyos proyectos afectan los territorios colectivos y ancestrales, así como los recursos naturales de propiedad de los grupos étnicos. ${ }^{2}$

La inexequibilidad de la Ley 1382 de 2010 fue desfavorable para la protección de áreas de especial importancia ecológica, como los páramos y humedales. Además, demostró el desinterés del Gobierno y del Congreso, quienes durante los dos años de la inexequibilidad diferida no se ocuparon de expedir una nueva ley que fuera más acorde con la protección del medio ambiente en los proyectos mineros, y que cumpliera los requisitos de consulta previa. ${ }^{3}$ No obstante, esta inexequibilidad no desprotegió totalmente los páramos y humedales. Estos ecosistemas se siguen considerando zonas de exclusión minera y áreas de especial importancia ecológica según los contenidos del Plan Nacional de Desarrollo 2010-2014 (L. 1450/2011, art. 202), ${ }^{4}$ el

2 La propiedad colectiva no solo se ejerce sobre la extensión territorial, sino sobre los recursos naturales no renovables allí existentes. Lo cierto es que la propiedad colectiva sobre los recursos naturales no da la facultad omnímoda para disponer libremente de ellos, pero sí obliga al Estado a ponderar la necesidad de aprovechar los recursos naturales, con el deber de protección de la integridad étnica y cultural (CConst., T-380/93, E. Cifuentes).

3 Para contrarrestar la inexequibilidad de la Ley 1382 se expidieron, por ejemplo, los decretos 0933 y 0934 de 2013. No obstante, el Consejo de Estado suspendió su ejecución.

4 A diferencia del Plan Nacional de Desarrollo 2010-2014, el Plan Nacional de Desarrollo 2014-2018 permite las actividades de exploración 
artículo 74 de la Constitución Política, tratados internacionales como la Convención de Ramsar sobre los Humedales de Importancia Internacional y otras normas ambientales nacionales como el artículo 1 de la Ley 99 de $1993^{5}$ y el artículo 28 del Decreto 933 de $2013 .{ }^{6}$

Al tener claros los conceptos de área de especial importancia ecológica y zona excluible de minería, se desarrolla a continuación la noción de título minero o concesión minera, así como los múltiples derechos en cabeza del concesionario minero. Esto con el fin de abordar posteriormente la discusión frente a los derechos adquiridos en temas de exploración y extracción de recursos naturales no renovables.

\section{EL TÍTULO MINERO O EL CONTRATO DE CONCESIÓN MINERA}

Desde la expedición del actual Código de Minas, los títulos mineros son los contratos de conce-

y explotación de recursos naturales en páramos para los contratos y licencias ambientales otorgadas con anterioridad al 9 de febrero de 2010 (minería) y al 16 de junio de 2011 (hidrocarburos). Esta disposición normativa es contraria a los compromisos nacionales e internacionales que ha adquirido Colombia a través del artículo 74 de la Constitución Política y la Convención de Ramsar, pues parte de que los titulares mineros tienen derechos adquiridos. Sin embargo, los derechos adquiridos no se consolidan en materia pública y ambiental, como se analiza a lo largo de este documento.

Las zonas de páramos, subpáramos, los nacimientos de agua y las zonas de recarga de acuíferos serán objeto de protección especial.

6 Cuando las áreas solicitadas se encuentren dentro de las áreas excluibles de la minería, de acuerdo con el artículo 34 de la Ley 685 de 2001, con las modificaciones introducidas por la Ley 1450 de 2011 respecto a las prohibiciones de realizar actividades mineras en ecosistemas de páramo teniendo como referencia mínima el Atlas de páramos del Instituto Humboldt, reservas forestales protectoras que no se pueden sustraer para estos fines, así como arrecifes de coral, manglares y humedales designados dentro de la lista de importancia internacional de la Convención de Ramsar, como tampoco en áreas incompatibles con la minería de acuerdo con el artículo 61 de la Ley 99 de 1993. sión minera. Sin embargo, antes de la entrada en vigencia de este Código, los títulos mineros podían ser licencias de exploración, licencias de explotación, aportes mineros ${ }^{7}$ y títulos expedidos con anterioridad al Decreto 2655 de 1988 (L. 685/2001, art. 14; Ricaurte, 2010, pág. 47).

El contrato de concesión minera es aquel que "se celebra entre el Estado y un particular para efectuar, por cuenta y riesgo de este, los estudios, trabajos, exploración y obras de explotación de minerales de propiedad estatal que puedan encontrarse dentro de una zona determinada" (L. 685/2001, art. 45). Este contrato, al estar definido y singularizado en la ley, se caracteriza por ser nominal y típico. También se identifica por ser solemne, bilateral, oneroso y de adhesión.

Tabla 1. Características del contrato de concesión minera

\begin{tabular}{|c|c|}
\hline $\begin{array}{c}\text { Nominal y } \\
\text { típico }\end{array}$ & $\begin{array}{l}\text { La ley lo identifica y singulariza frente a } \\
\text { otros negocios jurídicos, sobre todo fr- } \\
\text { ente al contrato de obra pública y de con- } \\
\text { cesión de servicio público (L. } 685 / 2001 \text {, } \\
\text { art. } 45 \text { ). }\end{array}$ \\
\hline Solemne & $\begin{array}{l}\text { Debe constar por escrito y en castellano, } \\
\text { además de que solo se perfecciona al in- } \\
\text { scribirse en el Registro Minero Nacional. } \\
\text { El registro del contrato tiene dos fines, el } \\
\text { primero de ellos es garantizar la oponibi- } \\
\text { lidad del negocio jurídico frente a ter- } \\
\text { ceros, y el segundo es producir efectos } \\
\text { en derecho (L. } 685 / 2001 \text {, art. } 50) \text {. }\end{array}$ \\
\hline
\end{tabular}

7 En los términos del artículo 48 del Decreto 2655 de 1988 se definió el aporte como "el acto por el cual el Ministerio otorga a sus entidades adscritas o vinculadas que tengan entre sus fines la actividad minera, la facultad temporal y exclusiva de explorar y explotar los depósitos y yacimientos de uno o varios minerales que puedan existir en un área determinada." 


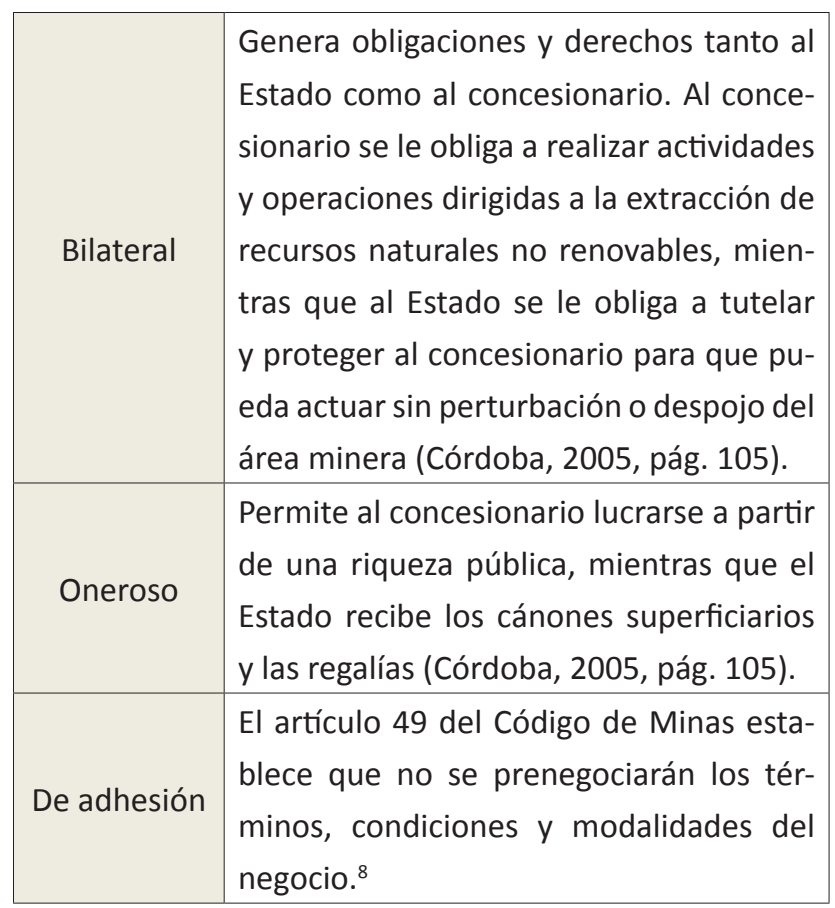

Fuente: elaboración propia con base en Córdoba (2005).

La concesión minera es un acto único que comprende todas las fases de la minería (L. $685 / 2001$, art. 45), incluyendo la explotación. No obstante, para el debido tránsito de la fase de exploración a la fase de explotación, debe presentarse ante la autoridad concedente el Programa de Trabajos y Obras (PTO) así como el Estudio de Impacto Ambiental (EIA), que permitirá a la autoridad ambiental decidir sobre la expedición de una licencia bajo los parámetros de la Ley 99 de 1993. Adicionalmente, la relación jurídica que nace del perfeccionamiento del contrato de concesión minera no transfiere al beneficiario un derecho de propiedad sobre los minerales in situ. La propiedad de los recursos naturales no renovables es exclusiva del Esta-

8 Por tratarse de un contrato de adhesión fue que se expidió la Resolución 420 de 2013 de la Agencia Nacional de Minería, por medio de la cual se establece y adopta la minuta de contrato único de concesión minera. do y solo podrán ser objeto de apropiación los minerales que se hayan extraído y captado ( $L$. $685 / 2001$, art. 15).

Finalmente, en el contrato de concesión minera se materializan todos los derechos que aparecen en el Código de Minas a favor del concesionario minero, que son los que se explican en la siguiente sección.

\section{EL ALCANCE DE LOS BENEFICIOS QUE EL CÓDIGO DE MINAS CONCEDE AL PRIMER SOLICITANTE Y AL TITULAR MINERO}

El Código de Minas otorga al concesionario minero una serie de derechos y beneficios cuya naturaleza y alcance parecen ilimitados, tanto así que el órgano constitucional ha tenido que interpretarlos para que no se conviertan en fórmulas absolutas de protección al concesionario, sobre otro tipo de compromisos ambientales y constitucionales. Esos derechos son:

\section{A. El Código de Minas consagra la aplicación preferente de sus disposiciones normativas}

El artículo 3 del Código de Minas prevé que su cuerpo normativo se aplicará en forma completa, sistemática, armónica, con el sentido de especialidad y de aplicación preferente cuando concurran conflictos o se aborden materias relacionadas con los recursos mineros. En la sentencia C-339 de 2002 se resolvió que tal disposición no contraría la jerarquía normativa del or- 
denamiento jurídico nacional -encabezado por la Constitución Nacional- sino que incorpora el criterio de ley especial, útil para dirimir las posibles antinomias que surjan entre la ley minera, civil, comercial, ambiental y de contratación estatal, así como los conflictos que se originen entre los particulares y el Estado.

La expresión "preferente" no hace prevalecer la ley minera sobre las normas constitucionales. Por el contrario, el criterio de especialidad que incorpora el Código de Minas respeta la jerarquía normativa debido a que:

i) Solo se aplica entre normas de igual jerarquía, por lo que no prevalece sobre los principios constitucionales, sino sobre otros cuerpos normativos de igual rango.

ii) La forma como se interpreten, apliquen e inapliquen las normas ambientales debe enmarcarse en las normas constitucionales protectoras del medio ambiente.

iii) La normatividad ambiental prevista en el mismo Código de Minas y en otras leyes ambientales deberá ser tenida en cuenta, siempre que no sea incompatible con la legislación especial minera y sirva para llenar vacíos o lagunas existentes en materia minero-ambiental (CConst., C-344/02, M. J. Cepeda).

iv) Cuando el principio de especialidad es insuficiente para dirimir conflictos de interpretación es posible acudir a otros principios superiores.

En ese sentido, el criterio de ley especial pretende dar seguridad jurídica al concesionario en el momento que se presente alguna controversia. Sin embargo, el alcance de esa protección siempre serán los contenidos de la Constitución Nacional, que es reconocida por la Corte Constitucional como "constitución ecológica" (CConst., T-411/92, A. Martínez), debido a que hace de la defensa del medio ambiente una necesidad universal y un principio rector dentro de la estructura del Estado social de derecho (CConst., C-431/00, V. Naranjo). Bajo ese entendido, la protección del medio ambiente es un principio constitucional de mayor valor frente a la normatividad minera.

\section{B. El Código de Minas impone un límite a las autoridades públicas para establecer y exigir permisos, licencias o requisitos adicionales para el desarrollo de la actividad minera}

El artículo 4 del Código de Minas $^{9}$ dispone que ninguna autoridad podrá establecer ni exigir permisos adicionales a los allí contemplados para la procedencia de la propuesta, la expedición, perfeccionamiento y ejercicio del título minero. Según la Corte Constitucional, esta norma materializa el criterio de especialidad, pues da prevalencia a los requisitos exigidos en el Código de Minas, por encima de los que pueda exigir la autoridad o la legislación ambiental. En últimas, el artículo 4 del Código de Minas dota de la coercibilidad necesaria a los mecanismos dirigidos a la protección y efectividad de los derechos del concesionario (CConst., C-344/02, M. J. Cepeda).

Véase también los artículos 18,47 y 48 que reiteran que al concesionario no se le puede exigir permisos, licencias y similares para el ejercicio de sus actividades de exploración y explotación. 
La exigencia de otros requisitos no dispuestos en el Estatuto Minero fue interpretada por el Consejo de Estado (CE, 3 feb. 2010, E. Gil) como una vulneración del derecho al debido proceso (CN, art. 29); principio que no solo se aplica en el contexto judicial, sino en los procedimientos administrativos (CConst., T-079/01, F. Morón). Así pues, la autoridad administrativa encargada de seleccionar al contratista de una concesión minera garantiza el debido proceso cuando atiende los requisitos exigidos por el legislador para el otorgamiento del contrato de concesión minera, sin adicionar exigencias que vulneren el factor de objetividad (CE, 3 feb. 2010, E. Gil).

Aunque el Código de Minas no le exige al concesionario licencias, permisos, trabajos o autorizaciones distintas a las allí referidas, este sí deberá respetar el derecho fundamental a la consulta previa que emana de un principio de carácter constitucional (arts. 2 y 330) y de tratados internacionales de derechos humanos, como lo es el Convenio 169 de la olt (arts. 6, 7 y 15). Se entiende, entonces, que el requisito de realizar la consulta no debe consignarse en todas y cada una de las leyes que versen de manera directa o indirecta sobre la explotación de recursos naturales yacentes en los territorios étnicos, "salvo que su no inclusión conduzca indefectiblemente a la conclusión de que la norma legal vulnera el parágrafo del artículo 330 u otro canon constitucional" (CConst., C-891/02, J. Araújo). ${ }^{10}$

10 El parágrafo del artículo 330 hace referencia al derecho de participación de las comunidades indígenas cuando se emprendan acciones de exploración y explotación de los recursos naturales dentro de sus territorios ancestrales.

\section{El Código de Minas crea para el futuro titular un derecho de prelación de la primera solicitud de propuesta}

El artículo 16 del Código de Minas dispone que al solicitar al Estado un título minero no se crea un derecho a la celebración del contrato de concesión, sino un derecho de prelación o preferencia. Para otorgar una concesión minera basta entonces aplicar el principio prior tempore, portior jure, ${ }^{11}$ que coadyuva a la estabilidad jurídica y constituye una forma objetiva de selección del contratista (Córdoba, 2005, pág. 106). Así lo consideró el Consejo de Estado, al establecer que los principios de transparencia y selección objetiva deben guiar todo procedimiento de contratación con la Administración Pública, así no se encuentren expresamente consignados en el Código de Minas (CE, 3 feb. 2010, E. Gil).

No obstante, también se ha estimado que la minería es una actividad que genera grave afectación ambiental y social, por lo que es cuestionable que en Colombia se otorguen títulos mineros sin rigor técnico ni jurídico, en la medida en "que no existe una cualificación del explotador minero y, por consiguiente, no existe un proceso de selección del mejor postor" (Negrete, 2013, pág. 23).

11 Primero en el tiempo, primero en el derecho. 


\section{El Código de Minas inaplica el Estatuto General de Contratación de la Administración Pública en los temas mineros}

El contrato de concesión minera no se rige por los preceptos de la Ley 80 de 1993. Esto se debe a que:

i) En el artículo 53 de la Ley 685 de 2001 el legislador excluyó la aplicación de las normas del Estatuto General de Contratación de la Administración Pública sobre formulación y trámite de las propuestas en la fase precontractual, la suscripción, perfeccionamiento, validez, ejecución y terminación del contrato.

ii) En el artículo 17 del Código de Minas se expresa que solo se aplicarán las disposiciones generales sobre la contratación estatal en temas de capacidad de las personas jurídicas, públicas o privadas, así como el régimen de inhabilidades e incompatibilidades.

iii) En el artículo 45 del Código de Minas se plantea la distinción entre contrato de concesión minera y contrato de obra pública y concesión de servicio público, que sí se guían por la Ley 80 de 1993.

iv) El artículo 51 del Código de Minas dispone expresamente que el contrato de concesión minera no podrá ser terminado, modificado o interpretado unilateralmente por parte de la entidad pública concedente.

La prohibición de aplicar el Estatuto General de Contratación de la Administración Pública impli- ca un beneficio para el concesionario, quien, de acuerdo con la Ley 685 de 2001, no tendrá que pactar cláusulas exorbitantes diferentes a la caducidad (art. 112) y la reversión gratuita a favor del Estado (art. 113). Como se sabe, las cláusulas exorbitantes tienen como finalidad romper la igualdad típica de los acuerdos de voluntad, a cambio de otorgar potestades extraordinarias a favor de las entidades estatales para disponer del contrato sin previa declaración judicial, y con el fundamento de proteger el interés público.

Dicho lo anterior, siempre que no haya lugar a la caducidad, el contrato de concesión minera solo podrá atacarse por declaración judicial. Adicionalmente, aunque en principio no se aplican los preceptos del Estatuto General de Contratación de la Administración Pública, es cierto que al momento de seleccionar al concesionario deben atenderse los principios de transparencia y selección objetiva contenidos en la Ley 80 de 1993. Esto se debe a que son principios y cánones de comportamiento que componen el derecho al debido proceso y que deben acatarse durante el procedimiento de escogencia del concesionario minero (CE, 3 feb. 2010, E. Gil).

\section{E. Según el Código de Minas, la minería es una actividad de utilidad pública}

El artículo 13 del Código de Minas considera que la minería y todas sus fases son actividades de utilidad pública. Esto facilita la constitución de gravámenes (L. 685/2001, arts. 4 y 13; L. 1450/2011, art. 108) y la expropiación a particulares de sus predios, si su tierra se encuentra en una mina (Orduz, 2012). No obstante, califi- 
car la minería un sector de utilidad pública acarrea las siguientes dificultades:

i) Produce conflictos sociales como el desplazamiento o la falta de comunicación a los propietarios sobre la existencia de solicitudes de titulación minera sobre sus predios (Garay, 2013, pág. 36).

ii) Desconoce la jerarquía de derechos previstos en el ordenamiento jurídico (Garay, 2013, pág. 36) y entra en tensión con otras situaciones también consideradas de utilidad pública, como es el caso del artículo 1 del Decreto 2811 de 1974, que expresa que:

El ambiente es patrimonio común. El Estado y los particulares deben participar en su preservación y manejo, que son de utilidad pública e interés social. La preservación y manejo de los recursos naturales renovables también son de utilidad pública e interés social.

iii) Resta prioridad a la actividad agropecuaria, que tiene protección más clara en la Constitución Nacional, a través de los artículos 64 y 65 . Estos artículos tratan sobre el acceso a la tierra para los trabajadores agrarios y sobre la especial protección para la producción de alimentos (Garay, 2013, pág. 20).

iv) Desconoce que la utilidad pública existente en relación con la explotación de recursos minerales no es un atributo de la actividad extractiva en sí, sino que tiene que ver con las obligaciones del Estado de racionalizar la economía y garantizar el mejoramiento de la calidad de vida de los habitantes del territorio colombiano (Vargas, 2013, pág. 77).

\section{F. Del título minero nace un derecho personal}

Finalmente, el artículo 15 del Código de Minas estipula que "el contrato de concesión minera y los demás títulos (...) no transfieren al beneficiario un derecho de propiedad de los minerales in situ”. Este artículo, entonces, supone que "al obtener el título minero nace el derecho personal $^{12}$ a explorar y explotar los recursos naturales no renovables" (L. 685/2001, art. 15), y, por tanto, plantea el problema de si ese derecho personal es o no un derecho adquirido en cabeza del concesionario minero, en el sentido que no puede modificarse la situación jurídica del titular minero ante un cambio normativo posterior. Esto obedece a que el derecho adquirido es un derecho personal individual, por cuanto "se han verificado todas las circunstancias y requisitos legales previstos" (CConst., C-168/95, C. Gaviria).

Al haber descrito los beneficios y derechos que el Código Minero otorga al concesionario minero, se exponen ahora los términos en los que se ha dado la discusión sobre la existencia e inexistencia de los derechos adquiridos en materia minera.

12 Según Margarita Ricaurte (2005), el derecho que confiere el título minero que otorga el Estado al particular es un derecho personal, toda vez que se trata de un derecho entre una persona (autoridad minera) y otra (concesionario). El derecho del concesionario no puede ser de carácter real, pues la propiedad respecto de los recursos naturales no renovables la detenta únicamente el Estado y así lo reiteran los artículos 5,6 y 7 del Código de Minas. 


\section{LA DISCUSIÓN SOBRE LOS DERECHOS ADQUIRIDOS DEL CONCESIONARIO MINERO}

Sobre los derechos adquiridos en materia minera se han desarrollado dos posturas. La primera establece que con el contrato de concesión minera efectivamente se consolidan derechos adquiridos. Esto se fundamenta en el artículo 332 de la Constitución Nacional, que expresa que el Estado es propietario del subsuelo y de los recursos naturales no renovables, sin perjuicio de los derechos adquiridos y perfeccionados con arreglo a las leyes preexistentes. La segunda postura, por el contrario, considera que no se consolidan derechos adquiridos en materia minera. Lo anterior se debe a que esta clase de derechos solo nacen con arreglo a las leyes civiles, lo que no es predicable de la relación jurídica que crea un contrato de concesión minera, pues, al involucrar la exploración y explotación de recursos naturales no renovables de propiedad exclusiva del Estado, se ubica en el ámbito del derecho público y no del derecho civil. En otras palabras, en ma- teria de derecho público la noción de derechos adquiridos tiende a diluirse, pues esta se refiere solo a los derechos que regulan las leyes civiles (CConst., T-001/92, A. Martínez). A continuación se explica con más detalles cuáles son los presupuestos y límites de estas dos propuestas.

\section{A. El contrato de concesión minera consolida derechos adquiridos}

Para saber si se consolidan derechos adquiridos en materia minera es fundamental saber qué es un derecho adquirido, qué clase de derecho es el que emana del contrato de concesión y cuáles son sus atributos.

Un derecho adquirido "es aquel que se entiende incorporado al patrimonio de la persona" (CConst., C-478/98, A. Martínez), por cuanto "se han verificado todas las circunstancias y requisitos legales previstos para atribuir o dar por nacido un derecho, aunque este no se haya aún ejercido o consumado" (CConst., C-168/95, C. Gaviria). 
Tabla 2. Características de los derechos adquiridos

\begin{tabular}{|l|l|}
\hline Subjetivo & Recae sobre un individuo[s] o persona[s]. \\
\hline $\begin{array}{l}\text { Concreto y con- } \\
\text { solidado }\end{array}$ & Ha cumplido los requisitos y condiciones que exige la ley vigente. \\
\hline Exigible & Se puede exigir en cualquier momento por parte del titular, incluso judicialmente. \\
\hline $\begin{array}{l}\text { Garantizado } \\
\text { jurídicamente }\end{array}$ & $\begin{array}{l}\text { Está protegido por la Constitución Nacional y ha sido desarrollado jurisprudencialmente por las } \\
\text { Altas Corporaciones. }\end{array}$ \\
\hline Intangible & $\begin{array}{l}\text { El legislador debe respetarlo cuando expida una nueva ley (CConst., C-983/10, L. E. Vargas). Adicio- } \\
\text { nalmente, un derecho adquirido se reconoce por no ser una mera expectativa }{ }^{13}, \text { ni una situación } \\
\text { jurídica protegible por el principio de confianza legítima. }{ }^{14}\end{array}$ \\
\hline
\end{tabular}

Fuente: elaboración propia.

Sobre la protección y alcance de los derechos adquiridos en materia minera se ha expresado que el Estado, aunque es el propietario del subsuelo y de los recursos naturales no renovables, ${ }^{15}$ debe respetar los derechos adquiridos que se derivan del contrato de concesión, de modo que

13 Por oposición al derecho adquirido, la mera expectativa es una situación consistente en la probabilidad de adquisición futura de un derecho que aún no se ha consolidado, porque no se han cumplido todos los requisitos legales. Esta probabilidad puede llegar a ser modificada o regulada por el legislador, quien deberá, de todas maneras, atender a los parámetros de justicia y equidad. Una situación en la que se ha considerado que no existen derechos adquiridos es durante el periodo de propuesta. En materia minera los derechos adquiridos solo existen al momento del perfeccionamiento del contrato de concesión. Así pues, durante el tiempo que hay entre la presentación de la propuesta y la firma e inscripción del contrato en el Registro Minero Nacional, se cuenta con una mera expectativa y con el derecho de prelación del artículo 16 del Código de Minas (CConst., C-242/09, M. González; Vargas, 2013, pág. 77).

14 El principio de confianza legítima surge para proteger al administrado frente a cambios bruscos e intempestivos por parte de las autoridades. El principio en cuestión se edifica sobre tres presupuestos básicos: (i) la necesidad de promover el interés público sin desconocer la buena fe de los individuos, (ii) una desestabilización cierta, evidente y razonable en la relación entre la administración y los administrados; y (iii) la necesidad de adoptar medidas por un período transitorio que adecuen la actual situación a la nueva realidad (CConst., T-458/11, J. Pretelt).

15 Sin consideración a que la propiedad, posesión o tenencia de los correspondientes terrenos, sean de otras entidades públicas, de particulares o de comunidades o grupos (L. 685/2001, art. 5). no se restrinja la ejecución de las actividades de minería más allá de lo establecido en el contrato y en las normas vigentes (CConst., C-983/10, L. E. Vargas). Esos derechos adquiridos surgen cuando se perfecciona el contrato de concesión minera, es decir, cuando ya se ha presentado debidamente la propuesta y se ha firmado e inscrito el contrato en el Registro Minero Nacional. En principio esos son los requisitos legales exigidos para que nazca a la vida un derecho adquirido en materia minera, el que toma mayor relevancia en virtud de las reglas de derecho según las cuales "en los contratos se entienden incorporadas las leyes vigentes en el momento de su celebración" (L. 153/1887, art. 38) y “todo contrato es una ley para los contratantes y no puede ser invalidado sino por su consentimiento mutuo o por causas legales" (CC, art. 1602).

Sin embargo, la protección que se da a las situaciones jurídicas consolidadas no es absoluta y por ello en la sentencia C-293 de 2002 se impusieron límites a la actividad económica y a la libre empresa, basados en: 
La primacía del interés general, bajo las condiciones del artículo $1^{\circ}$ [de la Constitución Nacional]. Al señalar que la propiedad privada [en este caso el derecho personal y patrimonial de explorar y explotar] no es un derecho absoluto, sino que "es una función social que implica obligaciones. Como tal, le es inherente una función ecológica" (art. 58, inciso 2). Además, señala la Constitución, que el Estado debe "prevenir y controlar los factores de deterioro ambiental, imponer las sanciones legales y exigir la reparación de los daños causados" (art. 80). Así mismo, establece dentro de los deberes de la persona y del ciudadano la obligación de "proteger los recursos culturales y naturales del país y velar por la conservación de un ambiente sano" (art. 95, ordinal 8).

En el mismo sentido, la jurisprudencia constitucional expresó que "los derechos adquiridos, aunque son ciertos, legítimos, subjetivos y protegidos legalmente, no son inmutables, pues encuentran límites en la utilidad pública o el interés social". ${ }^{16}$ Las Altas Cortes manifestaron que:

Tal afectación o desconocimiento [de los derechos adquiridos] solo está permitida constitucionalmente en el caso de que se presente un conflicto entre los intereses generales o sociales y los individuales, porque en este caso, para satisfacer los primeros, los segundos deben pasar a un segundo plano. Se trata de afirmar entonces el imperio del principio de que el bien común es superior al particular y de que, por lo mismo, este debe ceder (CSJ, 17 mar. 1997; CConst., T-451/92, C. Angarita).

16 Véase, por ejemplo, Corte Constitucional, sentencias C-983/10, L. E. Vargas y C-147/97, A. Barrera.
Ahora bien, se entiende que la minería no solo involucra intereses particulares que deben ceder ante el interés general, ya que se trata de una actividad de utilidad pública que entraña un interés común. No obstante, se debe tener en cuenta que, primero, la utilidad pública de la minería no está en la actividad extractiva sino en los beneficios sociales y de desarrollo que puede generar (Vargas, 2013, pág. 77). Y segundo, el órgano constitucional (sentencias T-428 y C-478/92) ha manifestado que es posible que entren en conflicto dos intereses de tipo general, caso en el cual tendría que resolverse a favor de aquel en el que se involucren derechos fundamentales más valiosos o importantes desde la perspectiva de los principios constitucionales. Es decir, que al haber entrecruzamiento de intereses generales, se deberá privilegiar aquel que concentre el mayor valor social.

Al enfrentar la actividad minera ${ }^{17}$ con la protección de las áreas excluibles de minería, ${ }^{18}$ estas últimas tienen mayor valor social porque por sus cualidades ecosistémicas están directamente vinculadas al derecho colectivo a un medio ambiente sano y a los derechos fundamentales al agua, la salud y la vida, entre otros. Ese valor especial de ciertos ecosistemas lo ha reconocido la Corte Constitucional en dos puntos. El primero de ellos es que la Constitución Nacional es una constitución ecológica (CConst., T-411/92, A. Martínez) que defiende el medio ambiente como un principio rector dentro de la estructura del Estado Social de Derecho (CConst.,

17 De utilidad pública.

18 También de utilidad pública según el Decreto 2811 de 1974 
C-431/00, V. Naranjo). El segundo de ellos, por su parte, es que "determinadas zonas por su valor arqueológico, histórico, cultural, social, étnico, biológico, etc., merecen una protección especial que justifica garantizar el ejercicio restringido de la minería" (Negrete, 2013, pág. 12).

Adicionalmente, la Corte Constitucional estableció que aunque la minería es una actividad de utilidad pública, esta debe "llevarse a cabo dentro de los límites que establece la propia Carta Política" (CConst., C-123/14, A. Rojas). Se deben tener en cuenta los límites y competencias que llevan a las autoridades a fijarse en la viabilidad técnica y ambiental de los proyectos mineros; en las decisiones de las autoridades locales y en los espacios de participación ciudadana, a través de los cuales se decide la vocación productiva de los territorios (CConst., C-123/14, A. Rojas). Bajo ese entendido, las actividades mineras solo pueden desarrollarse en "zonas donde su impacto ambiental pueda ser efectivamente prevenido, mitigado, corregido y compensado" (Negrete, 2013, pág. 45).

En síntesis, quienes defienden la tesis de la existencia de los derechos adquiridos en materia minera lo hacen en virtud de los artículos 58 y 332 de la Constitución Nacional. No obstante, esos derechos no son absolutos, pues se encuentran limitados a aquellos escenarios en que entren en conflicto los derechos de los particulares con la necesidad del interés público o social, o incluso cuando un interés general y público se enfrente a otro de la misma naturaleza, pero de mayor valor social.

\section{B. El contrato de concesión minera no crea derechos adquiridos}

La postura que plantea la inexistencia de los derechos adquiridos en materia minera se sustenta también en el artículo 58 de la Constitución Nacional, por medio del cual "se garantizan la propiedad privada y los demás derechos adquiridos con arreglo a las leyes civiles". Este contenido normativo tiene ciertas implicaciones sobre la naturaleza de los títulos mineros, ya que, al tener como objeto el uso y aprovechamiento de los recursos naturales no renovables de propiedad del Estado, no se inscriben estos en el contexto de las leyes civiles sino de las leyes de derecho público. Para explicar este punto se hará referencia al régimen de los recursos naturales renovables y no renovables y los efectos de obtener "derechos públicos subjetivos" (CConst., C-983/10, L. E. Vargas) sobre los recursos naturales no renovables.

El régimen de los recursos naturales es distinto a las normas de derecho civil aplicables a los bienes y a su negociabilidad (Jiménez, 2011 pág. 14). En la sentencia C-126 de 1998 se explica que la finalidad del Código de Recursos Naturales fue crear una legislación ambiental que sustrajera de la legislación civil ciertos asuntos relacionados con el uso de estos recursos. Lo anterior, "debido a que [la ley civil] se rige primordialmente por el principio de autonomía de la voluntad, que puede entrar en conflicto con la función social y ecológica de la propiedad" (CConst., C-221/97, A. Martínez). La creación de una legislación ambiental diferenciable de la legislación civil implica que los recursos per- 
tenecen a la Nación y que nadie puede alegar derechos absolutos, exclusivos, perpetuos e irrevocables sobre ellos. Otro factor que caracteriza el régimen público de los recursos naturales es que, por expresa disposición legal, el acceso, uso y aprovechamiento de los bienes de propiedad estatal solo es posible por medio de las figuras de permisos y autorizaciones sobre las que recae el derecho policivo del Estado (Jiménez, 2011 pág. 8).

El particular puede usar y explotar los recursos naturales renovables y no renovables, siempre que el Estado lo autorice y le conceda derechos especiales ${ }^{19}$ al concesionario, es decir, derechos públicos subjetivos de uso (CConst., C-983/10, L. E. Vargas). Ese derecho no transfiere al beneficiario la propiedad y no tiene un valor constitucional originario que pueda oponerse al Estado. Por el contrario, "cualquier titularidad proviene de este y tiene el alcance relativo que pueda en cada caso derivarse de las leyes" (CConst., C-221/97, A. Martínez). Al respecto, también se ha dicho que hay:

Una diferencia específica entre las situaciones jurídicas individuales o derechos subjetivos que emanan del derecho privado y las que se derivan de normas de derecho público. Mientras las primeras deben serle respetadas íntegramente a su titular por todos los demás particulares, por la autoridad y por la ley, que no puede vulnerarlos ni desconocerlos sino apenas regular su ejercicio, aquellas que nacen del derecho público son susceptibles de modificaciones en el futuro y aun de ser extinguidas

Que es un poder jurídico especial de uso del respectivo bien público. por obra de la voluntad legislativa en aras del interés supremo de la colectividad y de sus necesidades inmanentes de progreso y equilibrio social (CConst., T-001/92, A. Martínez).

Esto supone que las relaciones jurídicas que se crean para explotar recursos naturales no renovables, al ser de derecho público, no son definitivas ni consolidan derechos adquiridos. Esta noción solo se configura en aquellas circunstancias que regulan las leyes civiles. Las relaciones jurídicas que se forman bajo las leyes de carácter público tienden a ser provisionales, subordinadas al interés común y al derecho policivo del Estado (CE, 24 oct. 2002, G. Mendoza).

Un caso análogo que sostiene la inexistencia de derechos adquiridos en el ámbito del derecho público es la sentencia C-183 de 2003. Este fallo no hace referencia al contrato de concesión minera, sino a la concesión de bienes de uso público que es un negocio jurídico diferente. Sin embargo, este ejemplo es útil porque da por sentado que el contrato de concesión no otorga derechos adquiridos respecto de los bienes sobre los que recae el objeto del negocio jurídico, sino que es una situación precaria, temporal y rescindible, debido a razones de interés común:

Con todo, no resulta contrario a la Constitución que sobre los bienes de uso público se permita un uso especial o diferente, por parte de la Administración, a través del otorgamiento de concesiones o permisos de ocupación temporal, sin que por ello se transmute el carácter de público de esa clase de bienes. Es decir, que el otorgamiento de esa concesión o permiso 
para un uso especial en bienes de uso público por parte de los particulares, no implica la conformación de derechos subjetivos respecto de ellos, por cuanto la situación que se deriva del permiso o de la concesión es precaria, en el sentido de que son esencialmente temporales y por lo tanto revocables o rescindibles en cualquier momento por razones de interés general.

Del mismo modo, las sentencias C-604 de 2000 y C-822 de 2011 expresaron que la noción de derecho adquirido no tiene la misma connotación en derecho público que en derecho privado, debido a que en el primero prevalece el interés general sobre cualquier interés de carácter particular. Finalmente, la sentencia C-126 de 1998 señaló que el otorgamiento de una concesión para la explotación de recursos naturales no impide que la Administración intervenga posteriormente sobre la actividad que se realiza. Lo anterior se debe a que el interés público que acompaña este tipo de relaciones jurídicas involucra el deber de la Administración de vigilancia permanente sobre el concesionario, a fin de que cumpla adecuadamente sus obligaciones. Quiere decir esto que los derechos o situaciones jurídicas particulares sobre las que se aplica el derecho policivo del Estado no son absolutos, "de allí que como lo ha sostenido la Sala, no generen derechos adquiridos" (CE, 12 ago. 1999, J. Polo; CE, 24 oct. 2002, G. Mendoza).

Bien es cierto que estos precedentes jurisprudenciales no hacen referencia al contrato de concesión minera, sino a los contratos de concesión de bien de uso público y de explotación de recursos naturales. Sin embargo, se citan estas decisiones por dos razones. En primer lugar, porque la doctrina, la jurisprudencia nacional y el mismo Código de Minas no han sido muy claros en determinar si el contrato de concesión minera crea o no derechos adquiridos para el concesionario minero, razón por la cual es necesario recurrir a casos análogos que ayuden a resolver esta discusión. En segundo lugar, porque la Corte Constitucional sí ha sido clara al manifestar que los contratos de concesión que se rigen por el Estatuto General de Contratación de la Administración Pública no crean derechos adquiridos porque la Administración detenta sobre ellos su poder dispositivo y policivo. Siendo así, se muestra a continuación que la concesión minera comparte las mismas características que en su momento llevaron a la Corte Constitucional a considerar que las otras formas de concesión que se rigen por el Estatuto General de Contratación de la Administración Pública no crean derechos adquiridos.

\section{El poder dispositivo de la Administración}

Las sentencias que se citan sobre los contratos de concesión de explotación de recursos naturales renovables y bien de uso público consideran que no se crean derechos adquiridos en estos contratos, porque la Administración puede disponer unilateralmente de los negocios jurídicos. Bien es cierto que el contrato de concesión minera ha limitado gran parte de ese poder dispositivo al prohibir que se pacten la mayoría de cláusulas exorbitantes que prevé el Estatuto General de Contratación de la Administración Pública. No obstante, ese poder aún existe, pues se puede declarar la caducidad. 


\section{El poder policivo de la Administración}

Otra razón por la que la Corte Constitucional desvirtúa la existencia de derechos adquiridos en los contratos de concesión de bien de uso público y explotación de recursos naturales renovables es por la permanente vigilancia del ente estatal. En la ejecución de un contrato de concesión minera también está presente el poder policivo del Estado, como se cita a continuación:

El Estado es el administrador de los Recursos Naturales no Renovables, y cuenta con las tareas de titulación, control y fiscalización del sector (...) Las autoridades deben ejercer una permanente vigilancia sobre el concesionario, con el fin de que cumpla adecuadamente sus obligaciones, dentro del marco constitucional y legal fijado para la explotación de los recursos naturales no renovables con respecto a las normas ambientales (CConst., C-372/11, J. Pretelt).

\section{Los principios de concurrencia y la participación ciudadana}

Finalmente, se desvirtúa la existencia de derechos adquiridos en el desarrollo de la actividad minera, en virtud de la sentencia C-123 de $2014,{ }^{20}$ que condiciona la exequibilidad del artículo 37 del Código de Minas. Esta sentencia pone de manifiesto que en:

El proceso de autorización para la realización de actividades de exploración y explotación minera -cualquiera sea el nombre que se dé al

20 También se puede revisar la sentencia del Consejo de Estado que suspende el Decreto 934 de 2013 bajo el argumento de que se deben respetar los principios de concurrencia, participación y autonomía territorial cuando se trata de decidir sobre asuntos mineros y del subsuelo. procedimiento para expedir dicha autorización por parte del Estado- se tengan en cuenta los aspectos de coordinación y concurrencia, los cuales se fundan en el principio constitucional de autonomía territorial.

En otras palabras, para que se autorice cualquier actividad relacionada con la exploración y explotación de los recursos naturales no renovables, debe haberse garantizado la participación previa de la autoridad territorial (municipio o departamento), y no solo de la autoridad minera o ambiental.

Esta decisión judicial da cuenta de que la participación de los distintos niveles de la Administración es fundamental para que se pueda desarrollar cualquier actividad extractiva, de modo que no existe autonomía absoluta del concesionario minero y de la autoridad minera para decidir las condiciones de ejecución del contrato.

Dicho lo anterior, no se puede hablar de la consolidación de derechos adquiridos, cuando múltiples autoridades, en virtud del principio de concurrencia y del derecho de participación ciudadana, entran a definir la permisibilidad o no de las actividades mineras en un determinado territorio, así como las condiciones del proceso de exploración y extracción. Bajo tales principios, la autoridad territorial está facultada para tomar decisiones sobre el uso del subsuelo, con la concurrencia del nivel central y la autoridad ambiental y minera.

En síntesis, aunque la doctrina, la jurisprudencia y el Código de Minas no han sido claros respecto 
del surgimiento de derechos adquiridos cuando se obtiene un título minero, sí hay razones que llevan a pensar que este tipo de derechos no existen en el ámbito del derecho minero. Estas razones son el poder dispositivo y policivo que la Administración ejerce sobre los contratos de concesión minera.

\section{LA DILUCIÓN DE LOS DERECHOS ADQUIRIDOS DEL CONCESIONARIO MINERO EN LAS DIFERENTES ETAPAS DE LA ACTIVIDAD MINERA}

Como complemento a los anteriores argumentos, a continuación se exponen los diferentes escenarios de la actividad minera que exigen requisitos adicionales a la obtención del título minero para poder desempeñar tanto la exploración como la explotación de los recursos naturales no renovables del Estado. Los siguientes escenarios ponen en duda la existencia de los derechos adquiridos a explorar y explotar los recursos naturales no renovables. Esta sección muestra adicionalmente el tratamiento que algunas resoluciones y conceptos del Ministerio de Minas y Energía han dado a los concesionarios mineros cuando el área que se les ha titulado se declara zona de exclusión minera.

La actividad minera consta de tres etapas básicas: (i) la propuesta, (ii) la exploración y (iii) la etapa de montaje, construcción y explotación. La etapa de propuesta inicia en el momento de presentación de la solicitud del título minero y termina cuando se perfecciona el contrato de concesión minera. Por su parte, los trabajos de exploración deben iniciar cuando el contrato de concesión minera está debidamente inscrito en el Registro Nacional Minero, y terminan por vencimiento del término o cuando se presentan y aprueban el PTO y el EIA (Ricaurte, 2010, pág. 150). Finalmente, la etapa de montaje, construcción y explotación inicia después de obtener la licencia ambiental.

\section{Ilustración 1. Proceso de extracción minera}

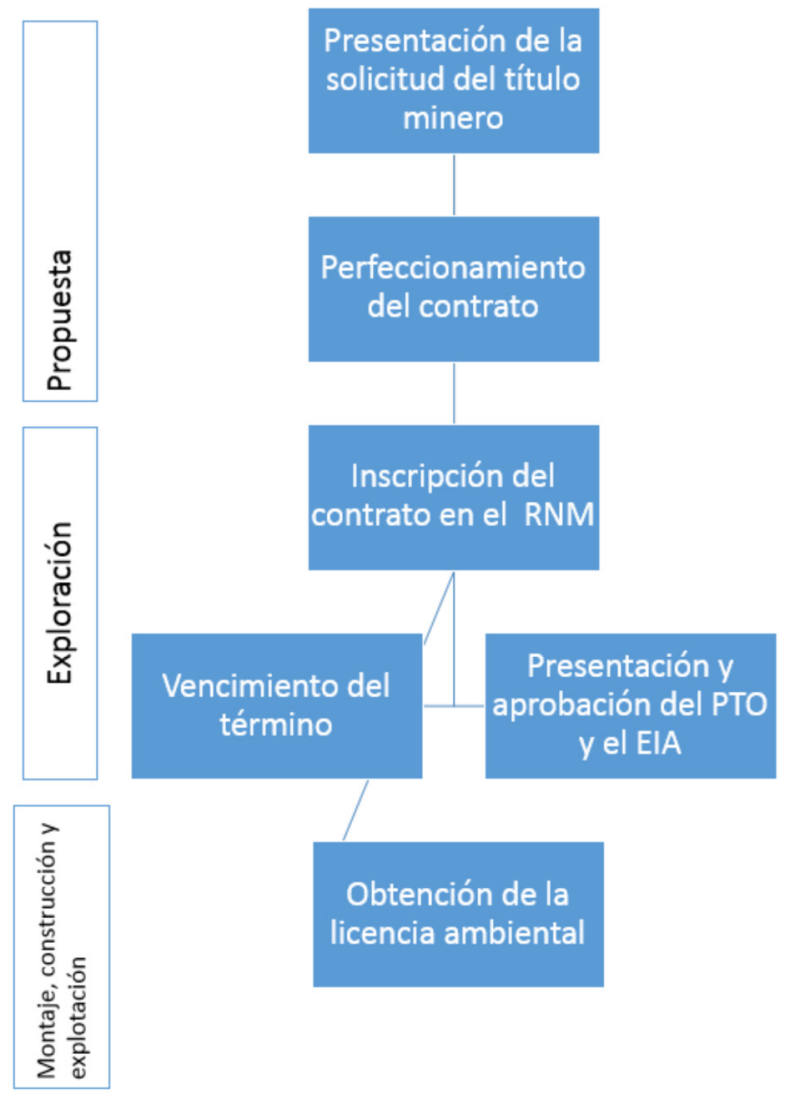

Fuente: elaboración propia con base en Ricaurte (2010).

Esto demuestra que aunque el contrato de concesión minera cubre todas las etapas de la actividad extractiva, lo cierto es que hay varios requisitos que se deben cumplir para que haya una transición entre una y otra etapa y para que, 
en ese sentido, pueda desarrollarse en forma adecuada la actividad minera. La existencia de estos requisitos, que se contemplan en el contrato de concesión minera, pero cuyo cumplimiento son independientes a él, ponen en duda la existencia de situaciones jurídicas consolidadas con la sola obtención del título minero. A continuación se muestran, etapa por etapa, los argumentos correspondientes.

\section{A. La propuesta}

La pregunta fundamental que gira en torno a la etapa de propuesta es si se pueden configurar derechos adquiridos antes del perfeccionamiento de un contrato de concesión minera. Lo que se ha dicho al respecto es que la propuesta es una situación jurídica en curso (MinMinas, Concepto. Rad: 22891 de 2010), de modo que no existe todavía una situación consolidada. Así pues, mientras la propuesta se encuentre en trámite y no se haya perfeccionado el contrato de concesión minera, no existen derechos adquiridos (CConst., C-983/10, L. E. Vargas). En ese sentido, los proponentes mineros no tienen derecho a explotar en zonas excluibles de minería y deben ajustarse a los cambios normativos (MinMinas. Conceptos, rad. 14764 y 45183 de 2010).

Según lo anterior, el problema jurídico se soluciona a favor de la inexistencia de derechos adquiridos en la etapa de propuesta, pero no bajo el argumento de que en el derecho público no se consolidan derechos adquiridos, como se ha defendido con anterioridad, sino porque no se han cumplido todos los requisitos de ley.

\section{B. La exploración}

En la etapa de trabajos de exploración tampoco se configuran derechos adquiridos por dos razones. Primera, porque el artículo 81 del Código de Minas exige al interesado adelantar la exploración de acuerdo con los términos de referencia y las guías mineras que para el efecto elaborará la autoridad minera. Al imponer ese tipo de exigencias para el desarrollo de la exploración, se visibiliza que el título minero no otorga la propiedad sobre los recursos naturales no renovables y que el Estado, en cambio, cuenta con un poder de vigilancia y control sobre las actividades del concesionario.

Segunda, porque en la etapa de exploración no se garantiza la futura extracción de los recursos naturales no renovables, ya que para ello se requiere: (i) la realización de estudios previos; (ii) la presentación y aprobación del PTO; (iii) la presentación y aprobación del EIA y (iv) la obtención de la licencia ambiental. En otras palabras, es claro que con el título minero no nace un derecho adquirido de explotación, pues no se han cumplido los demás requisitos de ley, como ha dejado por sentado la Corte Constitucional:

La existencia de un derecho adquirido (C.P. art. 58), independientemente de la materia jurídica objeto de regulación, se somete al cumplimiento riguroso de los supuestos jurídicos previstos en la ley. Así las cosas, mientras dichos supuestos no se consoliden completamente en el patrimonio de un sujeto a manera de consecuencia jurídica, este tan solo tiene la esperanza o probabilidad de obtener algún día los intereses o derechos individuales o sociales 
creados y definidos bajo el imperio de una ley, denominándose dicho fenómeno como mera expectativa (CConst., C529/94, J. Hernández).

\section{Etapa de construcción, montaje y explotación}

Para el debido tránsito de la etapa de exploración a la etapa de construcción, montaje y explotación se requiere la aprobación del PTO y del EIA, por ello, dentro de esta etapa se presentan al menos dos situaciones jurídicas. Una en la que se cumplen los dos requisitos enunciados y se obtiene la licencia ambiental correspondiente, y otra en la que no se cumplen los requisitos enunciados y por tanto se carece de la licencia ambiental. Del mismo modo, se presentan otras situaciones jurídicas que indagan sobre la minería en zonas excluibles de minería.

\section{Título minero vigente en etapa de explotación, pero sin el respectivo permiso ambiental}

La Corte Constitucional ha manifestado que “las solicitudes en trámite de actos administrativos que confieren permisos, licencias, autorizaciones y similares son simples expectativas" (CConst., C-983/10, L. E. Vargas; C-033/11, J. I. Palacio). En este sentido, aunque se cuente con un título minero, no se puede ejecutar ninguna actividad que implique la construcción, montaje o explotación de los recursos naturales no renovables, pues están condicionadas por la autorización que pueda expedir o negar la autoridad ambiental. La ausencia de la licencia ambiental implica entonces la ausencia de un derecho adquirido, ya que no se han cumplido los requisitos necesarios para que este nazca a la vida jurídica.

\section{Título minero vigente en etapa de explotación y con el respectivo permiso ambiental}

No nace a la vida jurídica un derecho adquirido cuando el titular minero cuenta con una licencia ambiental, pues se trata de un acto administrativo esencialmente revocable, y la Corte Constitucional ha expresado que:

Los actos administrativos que confieren permisos, licencias, autorizaciones y similares, son actos provisionales, subordinados al interés público y, por lo tanto, a los cambios que se presenten en el ordenamiento jurídico respectivo. Quiere decir ello que los derechos o situaciones jurídicas particulares nacidos de la aplicación del derecho policivo, no son definitivos y mucho menos absolutos, de allí que como lo ha sostenido la Sala, no generen derechos adquiridos (CE, 12 ago. 1999, J. Polo; CE, 24 oct. 2002, G. Mendoza).

Este planteamiento de la Corte Constitucional da cuenta de la tesis según la cual en el ámbito del derecho público no nacen derechos adquiridos, pues son situaciones que, a diferencia de aquellas creadas con arreglo a las leyes civiles, son esencialmente modificables por el poder dispositivo y policivo de la Administración, en aras de proteger el interés público. 


\section{Cambio normativo en etapa de construcción y montaje o de explotación con el PTO aprobado y con el respectivo permiso ambiental}

Un ejemplo que da cuenta de un cambio normativo que modifica las condiciones del concesionario minero fue la entrada en vigencia de la Ley 1382 de 2010. El artículo 3 de esta ley propuso un régimen de transición que respetaba el derecho de explotación (sin opción de prórroga) para aquellos títulos que, al momento de entrar a regir este cuerpo normativo, estuvieran vigentes, en etapa de explotación y contaran además con los debidos permisos ambientales.

Este antecedente legislativo es conflictivo porque da a entender que del título minero, cuando cuenta con licencia ambiental, nacen derechos adquiridos que no pueden ser perturbados por la expedición de una ley posterior. Sin embargo, no es cierto que nazca un derecho adquirido de esta circunstancia, pues la explotación del recurso natural no renovable está condicionada a un acto administrativo esencialmente revocable en virtud del interés general. Esto diluye la existencia de cualquier situación jurídica definitiva, como se mencionó con anterioridad.

\section{Los derechos adquiridos y la posterior declaratoria de reserva forestal protectora}

Otro ejemplo que favorece al concesionario minero frente a los cambios normativos es un concepto del Ministerio de Minas y Energía, respecto de la declaratoria de zonas de exclusión minera después de haberse perfeccionado un título minero. El problema jurídico que se extrae de dicho concepto es si el concesionario minero cuenta con un derecho adquirido sobre el área titulada, incluso después de la expedición de una resolución que declara un área de reserva forestal protectora. La solución que se da en el concepto es que:

En caso de declararse un área como zona de reserva forestal protectora, en la que de acuerdo con el artículo 34 de la Ley 685 de 2001 no es posible adelantar actividades mineras, se deberán respetar en todo caso aquellos títulos otorgados con anterioridad a la declaración del área, en tanto que ante dichos títulos nos encontramos frente a unos derechos adquiridos por parte de los titulares mineros, que no pueden ser desconocidos por normas posteriores.

Así pues, respondiendo a su inquietud podemos concluir que sí es posible legalmente que una Corporación Autónoma Regional delimite un área como zona de reserva forestal protectora en la que existen títulos mineros debidamente otorgados e inscritos en el Registro Minero Nacional, toda vez que pese a ser una exclusión sobreviniente, la misma no podrá desconocer derechos adquiridos por los concesionarios mineros en el área de afectación (MinMinas. Concepto. Rad: 26647 de 2012).

Este escenario es negativo frente a la tesis de que no se consolidan derechos adquiridos en el ámbito del derecho minero, pues mantiene indemne la relación jurídica inicial entre el titular minero y el Estado. Además de que no se especifica la etapa en la que se debe encontrar el título minero para poder desempeñar la actividad de 
explotación. En otras palabras, el concepto anteriormente citado no aclara si la ejecución del título minero está en su etapa de exploración, construcción y obras o explotación; o si se debe contar o no con una licencia ambiental. Afirmar que se crean derechos adquiridos por la sola inscripción del título minero en el registro equivale a olvidar que la exploración y la explotación están condicionadas por el poder dispositivo de la Administración y por otros requisitos legales, como la expedición de la licencia ambiental.

\section{El incumplimiento de los requisitos exigidos para desarrollar la actividad minera}

La Resolución 705 de 2013, prorrogada por la Resolución 1150 de 2014, es un caso que toca el tema de los títulos mineros dentro de zonas excluibles de minería. Esta resolución establece unas reservas de recursos naturales, pero con el condicionamiento de que "los bienes afectados por esta reserva quedarán excluidos solamente de nuevas concesiones o autorización de actividades mineras". El supuesto de este caso es peligroso y similar al que se expuso anteriormente sobre reservas forestales protectoras, pues se respetan las situaciones jurídicas creadas con el título minero, independientemente de la etapa en que este se encuentre o de si ya se presentó el PTO, el EIA o se cuenta con una licencia ambiental. En otras palabras, se asume que solo con la obtención del título minero se adquieren derechos que una resolución posterior no puede modificar, lo que va en contravía de la tesis sostenida en este texto.
Un último ejemplo es la Resolución 1197 de 2004, por medio de la cual se establecen las zonas compatibles con la minería de materiales de construcción y de arcillas en la Sabana de Bogotá. Esta resolución es importante porque contempla los diferentes escenarios que se pueden presentar en la etapa de explotación y las consecuencias por incumplir alguno de los requisitos ambientales. En primer lugar, la resolución divide los escenarios entre aquellos que se dan en zonas compatibles con actividad minera y los que se dan en zonas excluibles de minería.

Las circunstancias que se dan en zonas compatibles de minería, a su vez, se dividen en aquellas que cumplen los requisitos ambientales y las que no. En este texto son importantes aquellas circunstancias en las que no se cumplen los requisitos ambientales porque allí es donde se hace visible el problema con relación a la consolidación de derechos adquiridos. En la Resolución 1197 de 2004, el incumplimiento de los requisitos ambientales, aun existiendo el título minero, es una situación anormal que genera multas sucesivas y que podría llevar a la declaratoria de la caducidad por el incumplimiento grave y reiterado de cualquiera otra de las obligaciones derivadas del contrato (Ricaurte, 2010, pág. 149). En otras palabras, dicha resolución da cuenta de que una circunstancia de incumplimiento de los requisitos esenciales para el desarrollo de la explotación no está cubierta por un derecho adquirido. El incumplimiento supone que no se han verificado todos los requisitos de ley que puedan Ilevar al surgimiento de una situación jurídica definitiva. 
Respecto de los escenarios que se presentan en zonas excluibles de minería, la resolución en comento da prevalencia al titular minero cuando el área que se le otorga en concesión se declara una zona incompatible con la minería, pero siempre y cuando cuente con la licencia ambiental correspondiente. Dado el caso que el titular minero no tenga la licencia ambiental, pero se encuentre explotando el área concedida, se suspenderá la actividad minera. Ahora bien, si el título se encuentra en etapa de exploración, no se le podrá conceder en ningún caso la licencia ambiental y tampoco podrá desempeñar ningún tipo de actividad extractiva. La tabla 3 resume los escenarios y consecuencias de cada circunstancia jurídica contemplada en la Resolución 1197 de 2004.

Tabla 3. Escenarios jurídicos de la Resolución 1197 de 2004

\begin{tabular}{|c|c|c|}
\hline & Escenario & ¿Qué sucede? \\
\hline \multirow{4}{*}{$\begin{array}{l}\text { Minería } \\
\text { en zonas } \\
\text { com- } \\
\text { patibles } \\
\text { con la } \\
\text { actividad } \\
\text { minera }\end{array}$} & $\begin{array}{l}\text { Que cuenten con título, permiso u otra au- } \\
\text { torización minera vigente, incluida la autor- } \\
\text { ización ambiental. }\end{array}$ & $\begin{array}{l}\text { A la expedición de la resolución los titulares continuarán su } \\
\text { actividad minera y la autoridad ambiental competente real- } \\
\text { izará el seguimiento ambiental. }\end{array}$ \\
\hline & $\begin{array}{l}\text { Que cuenten con título, permiso u otra au- } \\
\text { torización minera vigente, pero carecen de } \\
\text { autorización ambiental, no han presentado } \\
\text { el Plan de Manejo Ambiental (PNM) y se en- } \\
\text { cuentran en explotación. }\end{array}$ & $\begin{array}{l}\text { La autoridad ambiental competente fijará los términos de } \\
\text { referencia para la elaboración del Plan de Manejo Ambien- } \\
\text { tal (PMA) por parte de los interesados. En caso de no presen- } \\
\text { tarse el PMA, la autoridad ambiental competente suspend- } \\
\text { erá la actividad minera. La autoridad ambiental competente } \\
\text { realizará el seguimiento ambiental (Ricaurte, 2010, pág. } \\
\text { 149). }{ }^{21}\end{array}$ \\
\hline & $\begin{array}{l}\text { Que cuenten con título, permiso u otra au- } \\
\text { torización minera vigente, pero carezcan de } \\
\text { autorización ambiental, aunque ya hayan } \\
\text { presentado el PNM, se encuentren explo- } \\
\text { tando y no cuenten con pronunciamiento } \\
\text { por parte de la autoridad ambiental com- } \\
\text { petente. }\end{array}$ & $\begin{array}{l}\text { La autoridad ambiental deberá pronunciarse y realizar el se- } \\
\text { guimiento ambiental. }\end{array}$ \\
\hline & $\begin{array}{l}\text { Que cuenten con título minero, permiso u } \\
\text { otra autorización minera vigente; que en } \\
\text { virtud de lo dispuesto en la Resolución } 222 \\
\text { de } 1994 \text { se encuentren en zonas compati- } \\
\text { bles y, además, tengan autorización ambi- } \\
\text { ental. }\end{array}$ & $\begin{array}{l}\text { Podrán continuar su actividad de acuerdo con el instru- } \\
\text { mento administrativo de manejo y control ambiental es- } \\
\text { tablecido. La autoridad ambiental competente realizará el } \\
\text { seguimiento ambiental. }\end{array}$ \\
\hline
\end{tabular}

21 Según la Ley 685 de 2001, para la explotación es necesario que se presente el pto y el pnm. Además, de debe contar con licencia ambiental antes de iniciar la explotación. Al incumplir los requisitos se pueden imponer multas sucesivas o declarar la caducidad por incumplimiento grave y reiterado de cualquiera otra de las obligaciones derivadas del contrato 


\begin{tabular}{|c|c|}
\hline & Escenario \\
\hline \multirow{5}{*}{$\begin{array}{c}\text { Minería } \\
\text { en zonas } \\
\text { com- } \\
\text { patibles } \\
\text { con la } \\
\text { actividad } \\
\text { minera }\end{array}$} & $\begin{array}{l}\text { Que cuenten con título, permiso u otra au- } \\
\text { torización minera vigente; que cuenten con } \\
\text { autorización ambiental y se encuentren en } \\
\text { explotación. }\end{array}$ \\
\hline & $\begin{array}{l}\text { Que cuenten con título, permiso o autor- } \\
\text { ización minera vigente; que cuenten con } \\
\text { autorización ambiental, pero no hayan ex- } \\
\text { plotado. }\end{array}$ \\
\hline & $\begin{array}{l}\text { Que cuenten con título, permiso u otra au- } \\
\text { torización minera vigente; que no cuenten } \\
\text { con autorización ambiental, pero hayan } \\
\text { venido explotando. }\end{array}$ \\
\hline & $\begin{array}{l}\text { Que cuenten con título, permiso u otra au- } \\
\text { torización minera vigente; que no cuenten } \\
\text { con autorización ambiental y no hayan efec- } \\
\text { tuado explotación. }\end{array}$ \\
\hline & $\begin{array}{l}\text { Que no tengan título, permiso o autorización } \\
\text { minera vigente; que no cuenten con autor- } \\
\text { ización ambiental y se encuentren en explo- } \\
\text { tación. }\end{array}$ \\
\hline
\end{tabular}

Fuente: elaboración propia.

Los anteriores ejemplos han tratado el problema de la declaratoria de una zona excluible de minería sobre un área que previamente se concedió a un titular minero. La postura predominante, no obstante, ha sido proteger al titular minero que se encuentra desarrollando actividades de explotación y que además cuenta con una licencia ambiental. Esta solución contraría los mandatos constitucionales de velar por un medio ambiente sano y de dar primacía a la protección de las
¿Qué sucede?

La autoridad ambiental competente entregará términos de referencia para elaborar el Plan de Manejo, Recuperación y Restauración Ambiental (PMRRA) del área. En caso que no se presente el PMRRA, la autoridad ambiental competente suspenderá la actividad minera. La autoridad ambiental competente realizará el seguimiento ambiental.

En esta circunstancia no se podrá adelantar la explotación.

La autoridad ambiental competente suspenderá de manera inmediata las actividades mineras y entregará los términos de referencia para la elaboración y presentación del PMRRA, para pronunciamiento por parte de la autoridad ambiental competente. La autoridad ambiental competente realizará el seguimiento ambiental.

La autoridad ambiental competente no podrá otorgar ningún tipo de autorización ambiental y en consecuencia no se podrá adelantar la explotación.

La autoridad ambiental competente suspenderá de manera inmediata las actividades, entregará términos de referencia para elaborar el PMRRA del área. Una vez se cumpla y se acepte el plan de restauración ambiental, la autoridad ambiental competente ordenará el cierre definitivo de la minería.

áreas de especial importancia ecológica sobre el desarrollo de las actividades productivas. Del mismo modo, contraría el argumento de que el título minero no es el único requisito necesario para que nazcan a la vida jurídica derechos adquiridos, pues a lo largo de la actividad minera deben cumplirse requisitos adicionales a él. Finalmente, va en contravía de la jurisprudencia constitucional, que ha expresado que los actos administrativos, en este caso las licencias ambientales, no pueden crear derechos adquiridos por ser esencialmente revocables. 


\section{CONCLUSIONES}

En el ordenamiento jurídico colombiano se protegen las áreas de especial importancia ecológica y las zonas excluibles de minería. Sin embargo, existen solicitudes y títulos mineros vigentes dentro de estas áreas. Esta circunstancia se presenta por las facilidades y beneficios que la legislación minera ha otorgado al titular y por la falta de certeza frente a la consolidación de derechos adquiridos en el ámbito del derecho minero.

A partir de ese problema el texto planteó el alcance de los beneficios que se encuentran en la legislación minera y la discusión en torno a la existencia o inexistencia de derechos adquiridos al obtener un título minero dentro de un área que se declara excluible de minería con posterioridad. Así pues, se llegó a la conclusión de que dado el caso que se adopte la tesis de que consolidan derechos adquiridos para el titular minero, estos tendrán que ceder ante otros principios de mayor valor social, como lo es la protección de áreas de alta importancia ecosistémica. Del mismo modo, se dejó en claro que los derechos adquiridos solo existen en el ámbito del derecho privado. El derecho minero, por su parte, se encuentra en el ámbito del derecho público, en el que no se consolidan situaciones jurídicas definitivas. Esto porque la Administración tiene la facultad de disponer y vigilar las relaciones jurídicas que establezca con el titular minero, en razón del interés general y de que conserva la propiedad de los recursos naturales no renovables.
Adicionalmente, se tuvieron en cuenta los diferentes escenarios y etapas de la actividad minera para poder determinar que en la propuesta, la exploración y la explotación no se consolidan derechos adquiridos. En la propuesta no nacen a la vida este tipo de derechos porque se trata de una situación jurídica en curso. En la exploración, por su parte, no hay un derecho adquirido a la explotación debido a que no se han cumplido todos los requisitos legales, como son la presentación del PTO, el EIA y la obtención de la licencia ambiental. Por último, en la explotación no se cuenta con un derecho adquirido de explotación, porque esta actividad queda condicionada a la vigencia de la licencia ambiental, un acto administrativo esencialmente revocable y modificable por parte de la Administración.

Finalmente, se hizo referencia a varios casos contenidos en conceptos y resoluciones del Ministerio de Minas y Energía y del Ministerio de Ambiente y Desarrollo Territorial o Ministerio de Ambiente y Desarrollo Sostenible. A partir de estos casos se mostró que prevalece la protección del titular minero en la etapa de explotación y con licencia ambiental, cuando posteriormente se declara una zona excluible de minería. No obstante, se da prevalencia a la protección de las zonas excluibles de minería cuando al titular minero le falta algún requisito por cumplir, ya sea: presentar y aprobar el PTO, presentar y aprobar el EIA u obtener la licencia ambiental. 


\section{Referencias}

Concepto jurídico. Rad. 22891 de 2010. [Ministerio de Minas y Energía]. Marzo 20 de 2010.

Concepto jurídico. Rad. 14764 de 2010. [Ministerio de Minas y Energía]. Marzo 25 de 2010.

Concepto jurídico. Rad. 45183 de 2010. [Ministerio de Minas y Energía]. Agosto 3 de 2010.

Concepto Jurídico. Rad: 26647 de 2012. [Ministerio de Minas y Energía]. Mayo 16 de 2012.

Consejo de Estado. Sala de lo Contencioso Administrativo. Sección Primera. Sentencia de agosto 12 de 1999. Expte. 5500 (C. P.: Juan Alberto Polo Figueroa).

Consejo de Estado. Sala de lo Contencioso Administrativo. Sección Primera. Sentencia de 24 de octubre de 2002. Expte. 4027 (C. P: Gabriel Eduardo Mendoza Martelo).

Consejo de Estado. Sala de lo Contencioso Administrativo. Sección Tercera. Sentencia de 3 de febrero 3 de 2010. Expte. 33187 (C. P.: Enrique Gil Botero).

Constituyente. (1991). Constitución Política de Colombia.

Convenio 169 de la oाt sobre pueblos indígenas y tribales en países independientes. Junio 7 , 1989.

Córdoba Pérez, J. M. (2005). La seguridad jurídica en el Código de Minas. En M. Durán Ca- macho, Temas mineros y petroleros. Bogotá: Colegio de Abogados de Minas y Petróleos.

Corte Constitucional de Colombia. Sentencia T-001 de 1992 (M. P.: Alejandro Martínez Caballero; abril 3 de 1992).

Corte Constitucional de Colombia. Sentencia T-411 de 1992 (M. P.: Alejandro Martínez Caballero; junio 17 de 1992).

Corte Constitucional de Colombia. Sentencia T-428 de 1992 (M. P.: Ciro Angarita Barón; junio 24 de 1992).

Corte Constitucional de Colombia. Sentencia T-451 de 1992 (M. P.: Ciro Angarita Barón; julio 10 de 1992).

Corte Constitucional de Colombia. Sentencia C-478 de 1992 (M. P.: Eduardo Cifuentes Muñoz; agosto 6 de 1992).

Corte Constitucional de Colombia. Sentencia T-380 de 1993 (M. P.: Eduardo Cifuentes Muñoz; septiembre 13 de 1993).

Corte Constitucional de Colombia. Sentencia C-529 de 1994 (M. P.: José Gregorio Hernández Galindo; noviembre 24 de 1994).

Corte Constitucional de Colombia. Sentencia C-126 de 1995 (M. P.: Hernando Herrera Vergara; marzo 22 de 1995).

Corte Constitucional de Colombia. Sentencia C-168 de 1995 (M. P.: Carlos Gaviria Díaz; abril 20 de 1995). 
Corte Constitucional de Colombia. Sentencia C-147 de 1997 (M. P.: Antonio Barrera Carbonell; marzo 19 de 1997).

Corte Constitucional de Colombia. Sentencia C-221 de 1997 (M. P.: Alejandro Martínez Caballero; abril 29 de 1997).

Corte Constitucional de Colombia. Sentencia C-126 de 1998 (M. P.: Alejandro Martínez Caballero; abril 1 de 1998).

Corte Constitucional de Colombia. Sentencia C-478 de 1998 (M. P.: Alejandro Martínez Caballero; septiembre 9 de 1998).

Corte Constitucional de Colombia. Sentencia C-431 de 2000 (M. P.: Vladimiro Naranjo Mesa; abril 12 de 2000).

Constitucional de Colombia. Sentencia C-604 de 2000 (M. P.: Carlos Gaviria Díaz; mayo 24 de 2000).

Corte Constitucional de Colombia. Sentencia T-079 de 2001 (M. P.: Fabio Morón Díaz; enero 29 de 2001).

Corte Constitucional de Colombia. Sentencia C-293 de 2002 (M. P.: Alfredo Beltrán Sierra; abril 23 de 2002).

Corte Constitucional de Colombia. Sentencia C-339 de 2002 (M. P.: Jaime Araújo Rentería; mayo 7 de 2002).
Corte Constitucional de Colombia. Sentencia C-344 de 2002 (M. P.: Manuel José Cepeda Espinosa; mayo 9 de 2002).

Corte Constitucional de Colombia. Sentencia T-666 de 2002 (M. P.: Eduardo Montealegre Lynett; agosto 15 de 2002).

Corte Constitucional. Sentencia C-891 de 2002 (M. P.: Jaime Araújo Rentería; octubre 22 de 2002).

Corte Constitucional de Colombia. Sentencia C-183 de 2003 (M. P.: Alfredo Beltrán Sierra; marzo 4 de 2003).

Corte Constitucional de Colombia. Sentencia C-242 de 2009 (M. P.: Mauricio González Cuervo; abril 1 de 2009).

Corte Constitucional de Colombia. Sentencia C-983 de 2010 (M. P.: Luis Ernesto Vargas Silva; diciembre 1 de 2010).

Corte Constitucional de Colombia. Sentencia C-033 de 2011 (M. P.: Jorge Iván Palacio Palacio; febrero 2 de 2011).

Corte Constitucional de Colombia. Sentencia C-372 de 2011 (M. P.: Jorge Ignacio Pretelt Chaljub; mayo 12 de 2011).

Corte Constitucional de Colombia. Sentencia. T-458 de 2011 (M. P.: Jorge Ignacio Pretelt Chaljub; mayo 31 de 2011). 
Corte Constitucional de Colombia. Sentencia C-822 de 2011 (M. P.: Mauricio González Cuervo; noviembre 2 de 2011).

Corte Constitucional de Colombia. Sentencia C-366 de 2012 (M. P.: Luis Ernesto Vargas Silva; mayo 16 de 2012).

Corte Constitucional de Colombia. Sentencia C-123 de 2014 (M. P.: Alberto Rojas Ríos; marzo 5 de 2014).

Corte Suprema de Justicia. Sentencia de marzo 17 de 1997 (M. P.: Eustorgio Sarria).

Decreto 2811 de 1974. [Presidencia de la República de Colombia]. Por el cual se dicta el Código Nacional de Recursos Naturales Renovables y de Protección al Medio Ambiente. Diciembre 18 de 1974.

Decreto 2655 de 1988. [Ministerio de Minas y Energía]. Por el cual se expide el Código de Minas. Diciembre 23 de 1988.

Decreto 0933 de 2013. [Ministerio de Minas y Energía]. Por el cual se dictan disposiciones en materia de formalización de minería tradicional y se modifican unas definiciones del Glosario Minero. Mayo 9 de 2013.

Decreto 0934 de 2013. [Ministerio de Minas y Energía]. Por el cual se reglamenta el artículo 37 de la Ley 685 de 2001. Mayo 9 de 2013.

Departamento Nacional de Planeación. (2014). Bases del plan nacional de desarrollo 2010-
2014. Prosperidad para todos. Bogotá, Colombia: DNP.

Garay, L. (2013). Globalización/glocalización, soberanía y gobernanza. A propósito del cambio climático y el extractivismo minero. En Minería en Colombia: fundamentos para superar el modelo extractivista (págs. 9-22). Bogotá: Contraloría General de la Nación.

Jiménez, M., Jiménez, N. y Puentes, A. (2011). Interés público de minería vs. interés público de protección ambiental: un debate constitucional. Bogotá: Asociación Interamericana para la Defensa del Ambiente.

Ley 153 de 1887. Por la cual se adiciona y reforma los códigos nacionales, la ley 61 de 1886 y la 57 de 1887. Agosto 15 de 1887. DO n. ${ }^{\circ}$ 7151 y 7152 de agosto 28 de 1887.

Ley 99 de 1993. Por la cual se crea el Ministerio del Medio Ambiente, se reordena el Sector Público encargado de la gestión y conservación del medio ambiente y los recursos naturales renovables, se organiza el Sistema Nacional Ambiental, SINA, y se dictan otras disposiciones. Diciembre 22 de 1993. DO n. ${ }^{\circ} 41146$.

Ley 685 de 2001. Por la cual se expide el Código de Minas y se dictan otras disposiciones. Agosto 15 de 2001. DO n. ${ }^{\circ} 44545$.

Ley 1450 de 2011. Por la cual se expide el Plan Nacional de Desarrollo, 2010-2014. Junio 16 de 2011. DO n. ${ }^{\circ} 48102$. 
Negrete, R. (2013). Derechos, minería y conflictos. Aspectos normativos. En Minería en Colombia: fundamentos para superar el modelo extractivista. (págs. 23-56). Bogotá: Contraloría General de la Nación.

Orduz, N. (Septiembre 2 de 2012). Las polémicas del Código Minero que tendrá que enfrentar Renjifo. Recuperado el 22 de enero de 2015 de lasillavacia: http://lasillavacia. com/historia/las-polemicas-del-codigo-minero-que-tendra-que-enfrentar-renjifo-35697

Resolución 1197 de 2004. [Ministerio de Ambiente, Vivienda y Desarrollo Territorial]. Por la cual se establecen las zonas compatibles con la minería de materiales de construcción y de arcillas en la Sabana de Bogotá, se sustituye la Resolución número 0813 del 14 de julio de 2004 y se adoptan otras determinaciones. Octubre 13 de 2004.

Resolución 705 de 2013. [Ministerio de Ambiente y Desarrollo Sostenible]. Por medio de la cual se establecen unas reservas de re- cursos naturales de manera temporal como zonas de protección y desarrollo de los recursos naturales renovables o del ambiente y se dictan otras disposiciones. DO n. ${ }^{\circ} 48.654$, de 17 de julio de 2013.

Resolución 1150 de 2014. [Ministerio de Ambiente y Desarrollo Sostenible]. Por medio de la cual se prorroga el término de duración de las Reservas de Recursos Naturales establecidas por la Resolución 705 de 2013. DO n. 49.214, de julio 16 de 2014.

Ricaurte, M. (2010). Código de Minas: comentado. Bogotá: Universidad Externado de Colombia.

Vargas Valencia, F. (2013). Minería, conflicto armado y despojo de tierras: impactos desafíos y posibles soluciones jurídicas. En Minería en Colombia: fundamentos para superar el modelo extractivista (págs. 57-88). Bogotá: Contraloría General de la Nación. 